\title{
THE DESTRUCTION OF THE “HOUSE”: CHANGING SOCIAL RELATIONS IN A RESTRUCTURED FACTORY
}

\author{
Alexander Castleton \\ M.A. Candidate, \\ Department of Sociology, \\ Carleton University, \\ Ottawa, Ontario, Canada
}

\begin{abstract}
This article explores the social changes within a dairy-products factory in Montevideo, Uruguay. Applying sociological research tools from ethnography and grounded theory, the data was collected through employment at the factory. My position as a temporary worker allowed me to interact with the many different individuals and social actors that made up the factory's social universe. I observed major organizational shifts within the human resources department, such as the hiring of younger and more educated prospects for supervisory roles, as opposed to filling those positions with the older and more experienced workers. This shift towards "productive re-arrangement" was a consequence of the regional and commercial challenges which encouraged strategic changes to keep the company competitive. The most obvious and significant changes were found in the hiring process, when the factory began increasingly targeting temporary workers for employment. In this article, I argue that these changes were largely responsible for a new spirit and emotionality that began to emerge amongst the current working pool; one of uncertainty and mistrust. When the dairy factory altered its operating philosophy, so did its labourers. This study looks to capture the relations that developed between them.
\end{abstract}

\section{INTRODUCTION}

7 his article examines the shifting micro-social interactions within a dairy products factory in Montevideo, Uruguay during a period of structural and organizational change necessitated by broader shifts in the economic-political context. This article is based on ethnographic fieldwork and employs grounded theory ${ }^{1}$ (Charmaz 2006) to understand the new meanings and interactions in the factory and their concrete impact on the daily lives of workers, supervisors and managers. The quotes used in this article come from in situ conversations which took place in different spaces of the factory; such as the workshops, the dining room, the locker room, the corridors, etc. 
The study examines hopes and fears, uncertainties and disorientations created in a social world where the workers are trying to make sense of their situation in times of change. Changes bring tensions and resistances, triggering new self-definitions of the actors. Thus, this paper explores and theorizes about the implications of change in the life-world of a particular factory.

\section{THEORETICAL PERSPECTIVES ON LABOUR AND PRODUCTIVE ORGANIZATIONS: UNDERSTANDING THE CASE OF THE URUGUAYAN FACTORY}

In the last twenty years, the productive sector in Uruguay has suffered modifications which entail flexibility of work, polyvalence of qualifications, innovation, creativity, and "just-in-time" ways of working. These changes are structural transformations that respond to national and international markets within an economic context which demands such re-arrangements in order to remain competitive (Neffa 1999). De la Garza (2000: 729) defines productive re-structuration as "the transformation of the socio-technical base of productive processes in different levels: technological, organizational, of work-management relations, and work-culture" ${ }^{2}$. Broader productive and organizational changes impact the specific dynamics of particular settings, and the Uruguayan factory has responded by altering its production processes. Frassa (2008) argues that current analyses in the sociology of work should encompass the shifting circumstances of production that lead to negotiations and rearrangements of a concrete working-environment. She further argues that "entrepreneurial-modernization strategies must be analyzed within the social context in which they occur, paying particular attention to the diversity of strategies and results. Thus, global structures have an influence but do not determine changes. In every context there is room for action" 3 (Frassa 2008: 10). According to this line of thought, productive changes must be examined, given the interplay of endogenous infactory dynamics which interact with exogenous local, regional, and global circumstances.

Thus, the broader dynamics impact the organization of productive units which, in turn, respond with re-arrangements in the structure of work-shops, human resources, and labour relations. Previous empirical studies of several in-factory realities help to put my observations into the context of shifting factory life-worlds. Burawoy (1979) has described how corporations manufacture consent through subtle and surreptitious methods of co-optation which, he argues, dilute class-consciousness and maximize productivity. Similarly, I would argue that the Uruguayan factory tries to create consent by increasingly hiring temporary workers who do not have the time-and would not take the risk-of relating to the union. Simultaneously, the company's strategy of increasingly hiring temporary labour separates workers by preventing the development of strong workplace bonds, thereby 
diminishing the organizational capacity of the union. This leads to tensions between temporary workers and the union and between the union and the company. Furthermore, Beaud and Pialoux (2001) observed intergenerational shifts of working cultures, habitus, and practices, when they studied the case of young workers in the Peugeot factory in Southern France. They point out that broader social circumstances - such as the extension of secondary education-alter the inside of the factory. Tensions also arise between older and younger workers, given the different approaches to worklife and social expectations. With respect to the Uruguayan factory studied here, the shifting productive circumstances led to changes which created a different type of worker with a different relative position towards collective action and capacities for negotiation.

In line with such work-shop ethnographies, this article explores the impact of productive and organizational changes in the life-world of a dairy factory.

\section{ETHNOGRAPHY IN THE FACTORY}

To undertake this study, I worked on the production line as a temporary worker. To avoid any ethical dilemmas, I disclosed my position as a researcher to both the workers and the union. As such, I played the role of a worker but took detailed field notes of workers" interactions and complaints as well as documenting my own experiences and responses to being employed in this environment.

The site of this study, a producer of dairy products, is a very significant player in the Uruguayan economy. In 2012, its exports to countries around the world were worth $\$ 500$ million US (Lomando 2013). The factory where I made my observations employed over 600 workers, while the parent company employs 1900 workers in total. In recent times, the number of female workers has increased significantly. However, few women, if any at all, were in decision-making positions in the union, a reality which is not in tune with the increasing number of female workers in the plant.

Following regional circumstances, the factory has gone through different processes of restructuring in the last decade which have shaken the foundations of the organization and affected the work patterns that factory employees were used to (Robertt 2006). This reality accompanies the productive change dynamics fostered by the insertion of Uruguay into the Southern Common Market or, in Spanish, Mercado Común del Sur (MERCOSUR) customs union and trading bloc that has integrated South America's Southern Cone region. This has promoted flexibility in production in order to remain competitive. It also led to productive and organizational re-arrangements in the industries which found themselves negotiating between cultural changes and the traditional ways of working in the factories (see Frassa 2008). The broader economic and political circumstances of the region provide a framework for understanding the shifting culture within the 
factory and the impact of new customs and practices on the daily lives of workers. These social dynamics are the focus of this article.

The ethnography took place in two of the most important departments within the factory: the ice cream and yogurt sectors. The social groups identified and observed in the factory include temporary workers, permanent workers, machinists, product-manufacturers ${ }^{4}$, maintenance workers (such as mechanics and electricians), and supervisors. The union's presence and role in this environment was also accounted for.

The union tried to protect temporary workers by implementing different strategies aiming at creating permanent positions and avoiding the over-use and abuse of temporary workers. The union defended the workers by fighting against organizational policies which weakened their situation. Their actions were directed at slowing the growing intensification of work, such as requiring the workers to take on more duties for the same wage, and fighting the company's requirement of increasing flexibility and multi-tasking among the workers.

Under the new regime, the constant production flow did not allow for free time or breaks, and workers were forced to be producing at all time. This differs from the "old days", when, according to the workers, the rhythms of production went at a slower pace and thus provided time for interaction and socialization among the workers. Under the new framework, the lack of interaction prevents the creation of identification with the union. One worker described that in the past there was a lot of time spent in the hallways and locker rooms, where politics and union issues were discussed. There is now a distance between the union and young workers. However, the union representatives of each sector, and not the supervisors, receive all the complaints or problems from within the workshops.

Temporary workers and permanent workers are both employed in the assembly-lines. The latter are those who have a permanent contract, meaning that they are assured a job for life as long as the company exists. These workers enjoy job security provided through the union, many benefits, protection from arbitrary firing, and a good salary compared to workers in other factories in Uruguay. Temporary workers, on the other hand, occupy an uncertain position, working under a six-month contract with the opportunity to be hired again for another six-month period. These workers face uncertainty since they are not guaranteed another six-month contract when their current contracts expire. For these workers, however, there is a slim chance of being "bridged" as permanent, putting an end to their uncertainty and anxiety over job security.

During the period of my observations, the ice-cream sector was the most productive at the time, given that it was January and temperatures reached 35 degrees Celsius on some days; the demand was large and hence the production was non-stop. My ability to occupy work positions in each line gave me the chance to experience the work and observe from every spot. It gave me the opportunity to engage in conversations with a diversity of 
workers and learn about their perspectives on the situation in the factory. My contact was more frequent with temporary workers, as that was my condition in the factory as well.

\section{THE IMPLICATIONS OF CHANGE IN THE FACTORY: FROM “THE HOUSE" TO AN ALIEN SPACE}

During my work period in the factory, I identified a certain pattern of attitudes and feelings embedded in a context of change. I will examine these patterns in the factory focusing on unfairness and mistrust which I identified as the main concerns felt by workers within a shifting factory culture. Although it is important to keep in mind the broad regional and economic picture, I will focus on the micro-social aspects of the day to day life in the factory ${ }^{5}$.

\section{CHANGE IN THE FACTORY: MANAGERS AND SUPERVISORS}

There have been changes in management in the company which affected the way things were traditionally done. Principally this was expressed by the old-timers who compared present-day relations within the factory to the past. For example, the former general manager knew the employees by name and identification number, and also knew their sons or fathers and in which factories they worked. Under the new regime, managers who were familiar with the workers were replaced by businessmen who were well-spoken and properly trained, but whose only interest revolves around production and profit ${ }^{6}$. Thus, for example, chatting with two workers in the smokers" sector of the patio during our break, one of them stated:

My father used to call [the company] "la casa" (home). In those times the former manager ${ }^{7}$ used to greet the workers by name and identification number; it was a different way of carrying out the company.

To what the other one added:

[The current manager] 8 only cares about production. He made radical changes in [the company], to the extent of even changing its logo as a symbol of renovation. He is only concerned with making the company work as it now does, say, hiring temporary workers all year long.

Presently, the atmosphere in the factory has become one of individualism rather than one of teamwork based on intimate connections and productivity has become the major work goal. The constant flow of temporary workers symbolizes of the goal of productivity, as they have to work hard if they want to be re-hired. One co-worker put it clearly when she warned me that temporary workers are used and then "thrown away." 
As mentioned above by one of the workers, the company used to be called "home" back in the day. This perception provided workers with an identity of common caring and support in the factory. For instance, I would often hear the fact that the old workers are sons of milk farmers who used to sell their produce to the factory, and eventually they were able to put their sons to work for the company. Also, I could hear in the locker-rooms, showers or smoking patios, the stories of the "good old times" in the factory, when one could get to work after having a few drinks, and the supervisor would tell the worker to lay down for a while and get back to work when the influence was over. Another example of the "better days" occurred when one respected old supervisor, who started as a temporary worker, told me that once he could count seventeen bottles of whiskey in the locker-room. This type of activity is now unthinkable; the rules of the house have changed, the opportunities to bend rules are almost non-existent, and the penalties for even trying are stiff.

From the stories I heard, I developed an understanding of the differences in how things were done in the past as opposed to the current daily expectations and tasks. My understanding of these differences was confirmed through the discourses of a number of different workers. Labour used to be more personal, manual and physical whereas now the lines of production, with the development of technologies, have rendered the human worker to the status of an "impersonal $\operatorname{cog}$ " in the production line conducting endless repetitive movements often performed standing in a single spot.

For these workers, the concept of change was expressed by a feeling of longing for the past that tended to romanticize worker-employer relations through images of "personal connections" and "good times". The situation now is one of alienation and powerlessness, in which the factory dehumanizes the workers. Under the new management, the person is a mere instrument of production. The shift is from the once "good old days" in which being at work equaled being at home, to an alien and instrumental place. The workers" subjectivity in the factory is now void of any substance; it leaves the workers adrift and alone, with no identity to define oneself. When talking to one supervisor, he made a diagnosis about the feeling of alienation:

I think that everybody here just cares about themselves, it is a problem of selfishness I would say. I don't understand why things have changed so much. Some time ago, [the company] was referred to as our "home", because it was the place that fed us.

Thus this kind of expression conveys feelings of estrangement in a new context that leaves workers alone. The house has been disrupted, and the endless flow of temporary workers increases the feelings of alienation. Such a flow of hundreds of people deprives human faces of familiarity, closeness and subjectivity. They just come and go so fast that it is worthless to take the time to know the temporary worker personally underneath the working robes and facemasks. 
Moreover, there have been changes regarding the higher management which affect the generality of the organization, but there have also been changes in the middle-managers in charge of the sectors. It affects the daily life of the line-worker because we had to interact with them on a daily basis as they assigned the position in the line we had to spend working on for the following nine hours. The main issue relating to this change came from the fact that sector supervisors were starting to be assigned from outside the pool of line-workers. For instance, in the ice-cream sector, a new supervisor had recently started to work there when I began my ethnography. She was a 26 year-old engineer who used to work in the laboratory of the factory and was promoted to work in production. The energy she demonstrated at work was admirable. However, she was not very appreciated by the workers. I could often hear comments of her being "arrogant" or "pig-headed"9. In contrast, other supervisors who had started their career as temporary workers then became permanent workers before they became supervisors, or in other words, who were not "parachuted" to the sector (a commonly heard expression amongst the workers), were considered differently in terms of respect. This fact changed the evaluations the workers had of them. For example, one co-worker told me something with the intention of giving me advice about working there. He referred to the new 26-year old supervisor, and his expression at the same time encapsulates the broader situation of change:

In order to work here you shouldn't be pretentious like the supervisor. You know...she came from outside...they are starting to bring in people with education as supervisors, and they don't know how things are done in here.

Another example is while talking with two co-workers, one told me:

[T] he supervisor here gives you orders but she doesn't know how the lines work...sometimes she orders you to develop two tasks at the same time.

Meanwhile the other one added:

[S]ometimes they don't understand the codes. They are educated people but they don't know how things are done here.

In contrast, there is a different perception of the supervisors not "parachuted" into the sectors. For instance, a worker told me on a different occasion:

I respect [the other supervisor] because he started like us, as a temporary worker. So he knows how the assembly-lines work...the others are different. They just graduate from "milk-school"10 and they are put in as supervisors.

Thus workers have experienced a change towards "unknowledgeable" supervisors and this has created a gap between those who are seen as 
outsiders and those perceived as insiders who understand the workers" culture; those who have gained careers from the outside versus the new young technicians hired by the factory from the outside. Significantly, being an insider-supervisor entitles the supervisor to the symbolic authority of being able to say certain things that young technician-supervisors cannot. For example, on one occasion I was peacefully chatting with one of the old workers who was an important member of the union. A young male supervisor in his late twenties, who was a milk technician, told us as he passed by, ironically but with no bad intention: "don't work too hard you two". This comment annoyed the old worker who appeared to be outraged because this young outsider supervisor had made this comment. This sense of outrage describes the struggling relations of power that have emerged in the factory due to structural changes and exemplifies how each position provides a certain habitus, using Bourdieu's concept (1989), embedded in the structural position in the factory. Insider experience provides knowledge, and knowledge brings along respect. These different positions of power can be seen as opposed to other situations. For example, while working on a line with a well-known union deputy, an old supervisor who had started as a temporary worker 35 years ago approached us and patted the union deputy on the shoulder. Then he looked at me and said: "This is my favorite communist". The union deputy corresponded with a smile. This kind of confidence is unthinkable from someone who does not have the symbolical authority to say such things; it is an authority gained through years of working on the lines. The changing situation now, regarding new supervisors, was disrupting such interactions. The new circumstances foster an environment of distrust and feelings of unfairness.

These changes in the factory's production and organization have deeper implications for the workers, requiring new processes of accommodation to the circumstances. In this context, tensions, confrontations, and the emergence of new feelings are a constant. In the following section I will discuss the concept of unfairness as it emerged from the data.

\section{“ENTREPRENEURIAL ANIMALS"11}

The expression, "entrepreneurial animals", came from a chat I had in the smoker's sector of the patio with an old worker who was the leader of the union. He also used the word "scavengers" to refer to the company. The words used refer to a feeling of facing something that lacks humanity and compassion, a sort of conscious-less creature which has no interest in the dignity of the human components of the organization. It is the feeling of alienation that comes from being a number in the payroll of the "enemy", a faceless machine, whose sole purpose is to squeeze every little bit of energy from the workers for the sake of efficiency and increasing production.

This attitude involves a perception of exploitation and alienation in an organization that is trying to surf through broad structural economic changes, 
changes which have concrete human implications in the factory. The cognitive reference is lost; the factory is no longer "the house." The job seems to be meaningless to the workers on the lines who are expected to simply pack ice-cream products into boxes for nine hours a day. Change brings along feelings of unfairness in the situation. Temporary workers are adrift in the sectors; some of them do not know why they have been contracted temporarily four, five, or even thirteen times without being hired permanently. They come up with some hypotheses from this, such as, "maybe I am stupid", or, "they don't like me", to accompany their feelings of desperation, confusion and low self-esteem.

As a temporary worker myself during the period of my ethnographic study, I could feel the pressure and competitiveness among us in that category of workers. This is because temporary workers are always being rated by the supervisors. At the end of the contract, every temporary worker is given his or her final "grades" in a series of items. The grades are very important in order to be called again for another six-month period of work, or to be lucky enough to be permanently hired. Thus, questions arise, such as: "why was he/she hired instead of me?" or "what did he/she do different from me?" The "grading" and "testing" of the temporary workers contributes to an environment of unfairness and uncertainty. Further, the constant surveillance creates anxiety as workers carefully watch their steps, hoping to avoid being spotted doing nothing through the supervisor's office window, which strategically allowed a bird's-eye view of the whole sector in a Benthamic panopticon (see Foucault, 1975/2008). Wanting to appear to be busy at all times, we washed the floor when the machines stopped (a mandatory temporary worker task) over and over again, even though it had already been cleaned. The fear of being spotted with nothing to do was dreadful. When I asked a co-worker what to do when the machine stopped for half an hour, the reply was: "grab a broom and pretend you're doing something".

While working on the line, one of my fellow temporary workers put it very clearly: "the company sucks away your youth and energy"; it uses us and then throws us away as a disposable tool. Workers regard this situation as unfair. But of course, the company has to remain competitive, and the temporary workers, who are completely powerless, have no choice but to continue to work hard, hoping to be rewarded with permanency one day or at the very least, another six months on the job. Their position leaves them with no option but to do what they are told.

Besides differences in institutional structures for each category of workers, there were profound real differences experienced by temporary and permanent workers in the plant's atmosphere, although there were tacit arrangements between both. For instance, when a machine stopped unexpectedly, permanent workers just stayed in their positions and did nothing, whereas temporary workers rapidly had to find something to do in order to prove their efficiency, productivity, and creativity. Temporary 
workers could not be seen to be wasting time. Thus, we started washing the clean floors again, trying to find garbage to put in the bags, or just pretending we were doing something useful. But the main difference was the lack of protection temporary workers had from the union. The temporary workers felt that the union gave lip-service to their cause, stating that it cares about their situation, when in reality the union did nothing for the temporary workers. Thus, unfairness permeated the factory landscape. For the temporary workers, the unfairness of their positions and tasks they were assigned, clashed with the appearance of partnerships and the feelings of camaraderie that the union tried to develop on a discursive level.

The data shows how shifting circumstances have repercussions on the daily interactions and relationships of the workers, which prompt perceptions of unfairness in the factory's social world. This context was a fertile field for an environment of general mistrust in the social relations between workers themselves, between the workers and every level of management, and between the workers and the union. In the following section, I will examine the feelings of mistrust I observed in the factory.

\section{THE FACTORY AS A “CHESS GAME"}

My position on the line consisted of ensuring that the ice-cream bars travelled properly through the line to be packaged. On one occasion as everything was under control, I went to chat with the machinist next to me. There had been some issues the day before involving a worker disobeying an order from management, an additional problem to the numerous others discussed by the union at the time. The machinist described the situation as a chess game, given the strategies and the calculated movements that the machinist attributed to the relations between both actors. This metaphor refers to a battle in which each side surreptitiously tried to undermine the other, in a way that each movement, word, or change from either side, was felt as part of a conspiracy with the goal of harming the workers or the company's interest. This skepticism relates to a mutually perceived lack of humanity amongst the actors, in the sense of an instrumental rationality used to attack the other. When a demand is posed to the director of the sector by the union, it has to go up the hierarchy and then comes back down to the floor with its resolution. Most of the time the process is slow or nonexistent, causing tension for the workers.

Moreover, the workers felt that they were disregarded when decisions were made for the sectors of the factory. In a sense, it was an invasion of the territory where they spent most of the day, some of them for decades. Thus the resolutions management made about, for example, things like changing a line of production or its disposition, or installing new machinery, altered the space inhabited by the workers. A concrete example of this was a line which had been recently installed in the middle of the packaging and storage part of the sector, which reduced visibility for the forklift-drivers and hence became 
hazardous for the workers. One worker expressed angrily during a conversation: "The engineers who designed this should be killed".

Decisions made by management without consulting the workers represented a lack of respect and a refusal to acknowledge the worker's opinion about their own workplace, thereby feeding the feeling of mistrust. The workers resented being ignored and dismissed, especially when they have the actual knowledge of the sector, whereas the engineers are very distant from that reality. The lack of recognition was both real and symbolic, and contributed to a growing atmosphere of mistrust as the workers, many of whom had been there for decades, had many ideas about the changes that took place in their sectors ${ }^{12}$. Management's changes represented an alteration of the space perceived by the workers as their own. Overlooking the workers' opinions consequently drove a de-subjectivization of the workplace. Therefore, feelings of unfairness and mistrust were a comprehensible outcome of such situations.

Further widening the perceptions of mistrust was the fact that temporary workers were always under pressure of being "graded" by the supervisor made for an environment in which workers sometimes mistrusted one another. Under the constant pressure to prove themselves worthy of a possible promotion to permanency, temporary workers strove to stand out from the rest. The presence of a supervisor evaluating one's moves was always there, provoking co-workers to be suspicious of everything they heard, even comments said as a joke or with a friendly tone.

The mistrust was also expressed in a more "horizontal" realm, between workers and the union ${ }^{13}$. I could often hear comments about how the union only minded their own business, and cared for their own interests. The trivialities that sometimes the union discussed in the meetings were a source of annoyance and a sign that they were for the union director's sake only. For instance, a worker told me once that he overheard a meeting taking place in the factory's dining room, and the discussion involved how much union money the executive could spend on cell-phone calls. Also, the actions that the union undertook were sometimes contrary to the interests of the temporary workers and sparked concerns that the company will not hire any more temporary workers. These incidents made the workers believe that the union was sometimes more of a risk than a source of security, and that its actions worked against them rather than for them.

The observations made during the study demonstrate a growing sense of alienation in a changing factory. These feelings come from the relation between workers and management, between the workers and the union, and among workers themselves. Coupled with the new business philosophy and practices of the factory, this fostered the deterioration of the social relations within the factory and fed a generalized perception of unfairness and mistrust. 


\section{CONCLUSIONS}

This article is the result of ethnography which explored implications that changing circumstances have had on a dairy factory in Montevideo, Uruguay. My role in the factory was of an overt temporary worker. This allowed me to have the same experiences that the workers have in their daily lives within the setting. The main observations that emerged from the data were feelings of unfairness and mistrust.

I argue that the implications of change in a particular factory should also be considered on a general plane in order to complete the picture. In the last 20 years, to remain competitive in the national and international market, the productive sector in Uruguay incorporated new processes which entail flexibility, polyvalence of qualifications, innovation, creativity and "just in time" ways of working (Neffa 1999). Thus, the interplay between the macro and micro realities provide a clear explanation of the current situation in the factory (Beaud and Pialoux 2001).

Broader productive and organizational changes impact the specific dynamics of a particular setting, and the Uruguayan factory is no stranger to these changes in the way(s) of production. Shifting ways of production have concrete implications on the actors and the interactions amongst them. The new processes require in-factory cultural re-negotiations. Consent with this reality is produced when workers assume that being temporary workers is their reality, and that being hired permanently is a very distant goal (Burawoy 1979). Thus, a worker strives only to satisfy the supervisor with the hope that next time he or she will be hired permanently. Therefore, workers are atomized and, as a result, an atmosphere of unfairness and mistrust characterizes the Uruguayan factory.

\section{NOTES}

1 This technique involves the task of constantly comparing data from the outset of the research, comparing new data with emerging categories, and demonstrating the relation between concepts and categories.

My translation from Spanish.

Ibid.

4 These types of workers have certain know-how that the regular permanent worker do not, such as recipes. They are also in charge of operating computers and informatics systems which manage faucets and pipelines.

5 My own observations as well as conversations with workers, supervisors and managers - acquiring the shape of undirected interviews (Gruber 2011), and field notes in general, were the techniques applied to gather data in the field. Also, constant comparison, memo-writing, relating categories, reflexivity, etc, helped for the identification of the main issues for the construction of the grounded theory (see Hall and Callery 2001; Walker and Myrick 2006; Charmaz 2006; Giske and Artinian 2007). 
6 The ideas presented here where conveyed by workers in different occasions and settings (working in the line, on the dining room, locker rooms, etc.).

7 He actually says the former manager's last name.

$8 \quad$ Ibid.

9 The Spanish expression I heard was that she was "cabeza dura". I believe that pig-headed would be the best translation.

10 In Uruguay there is a branch of the State's trade school focused on dairy production. It is known as milk-school.

11 This is the translation of the expression "animalismo empesarial" in Spanish.

12 Although the lack of acknowledgement could be interpreted to refer to the traditional Taylorist-Fordist notion of separation of workers: those in charge of knowledge-based activities and the line workers (see, for instance, Frassa 2008; Coriat 1982). However in this article I focus on the micro-context and interactions in the factory from a symbolic interactionist approach (Blumer 1969).

13 Again, a deteriorating perception and presence of the union also refers to the macro-context of productive and organizational change from Taylorist-Fordist organizations towards newer ones which render an individualized worker (see Frassa 2008 and Neffa 2000).

\section{REFERENCES}

Beaud, S. and M. Pialoux. 2001. "Between Mate and Scab. The contradictory inheritance of French workers in the postfordist factory." Ethnography 2(3): 323-355.

Blumer, H. 1969. Symbolic Interactionism. Englewood Cliffs: Prentice Hall.

Bourdieu, P. 1989. Social Space and Symbolic Power. Sociological Theory $7(1): 14-25$.

Burawoy, M. 1979. Manufacturing Consent. Changes in the Labour Process under Monopoly Capitalism. Chicago: The University of Chicago Press.

Charmaz, K. 2006. Constructing Grounded Theory. A Practical Guide Through Qualitative Analysis. Thousand Oaks: SAGE Publications.

Coriat, B. 1982. El taller y el Cronómetro: Ensayo sobre el Taylorismo, el Fordismo y la Producción en masa. Madrid: Siglo Veintiuno.

Lomando, L. 2013. “Conaprole se adelanta al futuro y va por más producción." El Observador. Accessed May 29 2014:

http://www.elobservador.com.uy/noticia/241500/conaprole-se-adelanta-alfuturo-y-va-por-mas-produccion/

Foucault, M. 2008 [1975]. Vigilar y Castigar: nacimiento de la prisión. Buenos Aires: Siglo Veintiuno.

Frassa, J. 2008. "Tendencias globales y locales en los nuevos modelos de producción y organización del trabajo. Apuntes para la discusión." Trabajo y Sociedad. Indagaciones sobre el trabajo, la cultura y las prácticas políticas en sociedades segmentadas 11(10): 1-14. 
81 Just Labour: A Canadian Journal of Work and Society - Volume 21 - Spring 2014

Geske, T. and B. Artinian. 2007. “A Personal Experience of Working with Classical Grounded Theory: From Beginner to Experienced Grounded Theorist." International Journal of Qualitative Methods 6(40): 67-80.

Guber, R. 2011. La etnografía, método, campo y reflexividad. Buenos Aires: Siglo Veintiuno.

Hall, W. and P. Callery. 2001. "Pearls, Pith, and Provocation: Enhancing the Rigor of Grounded Theory: Incorporating Reflexivity and Relationality." Qualitative Health Research 11(2): 257-272.

Neffa, J.C. 1999. “Crisis y emergencia de Nuevos Modelos Productivos" Pp. 39-70 in Los retos teóricos de los estudios del trabajo hacia el siglo XXI, edited by Enrique de La Garza Toledo. Buenos Aires, Argentina: CLACSO, Consejo Latinoamericano de Ciencias Sociales.

Robertt, P. 2006. Reestruturação Produtiva e Social em uma Empresa Globalizada. O caso de Conaprole no Uruguai. Doctoral Thesis, Universidad Federal Rio Grande do Sul, Porto Alegre, Brasil.

Walker, D. and F. Myrick. 2006. "Grounded Theory: An Exploration of Process and Procedure." Qualitative Health Research 16(4):547-559. 